Active and Passive Elec. Comp., 2002, Vol. 25, pp. 71-82

\title{
SMALL ANTENNAS FOR WIRELESS MICRO-SYSTEMS
}

\author{
Requirements, State of the Art, Future Trends \\ RAINER WANSCH* \\ Fraunhofer Institut Integrierte Schaltungen, Erlangen, Germany
}

(Received 6 November 2001; In final form 3 December 2001)

\begin{abstract}
This paper will describe the topology of wireless micro-systems networks and some of their key components. In particular we will deal with the antennas: loops, helices, F-antennas, patches and dielectrically loaded antennas.
\end{abstract}

Keywords: Wireless micro-systems network; Small antennas

\section{INTRODUCTION}

In the field of automation and control technologies as well as in the field of transport and logistics there is a growing demand for distributed autonomous micro-systems. A focus point of these applications is wireless transmission of data and energy from and to these micro-systems.

There are especially applications within the field of health. One can think of wireless sensors nearby the human body to track the vital functions like blood pressure, oxygenation levels, heart frequency etc.

We will have to distinguish in principle between different application scenarios:

- free space scenario: wide spread, long distance transmissions necessary

- indoor scenario: still long distance transmission necessary

- short range scenario: data and energy transmission within the range of $1 \mathrm{~m}$

- body area network: transmission nearby the human body

For each scenario there will be different topologies for the network and micro-systems. Within the field of long range transmissions one will have to work with active micro-systems whereas within the short range and body area field there is also the possibility of passive micro-systems.

* Tel.: ++49 (0)9131/776-385; Fax: ++49 (0)9131/776-399; E-mail: wan@iis.fhg.de 


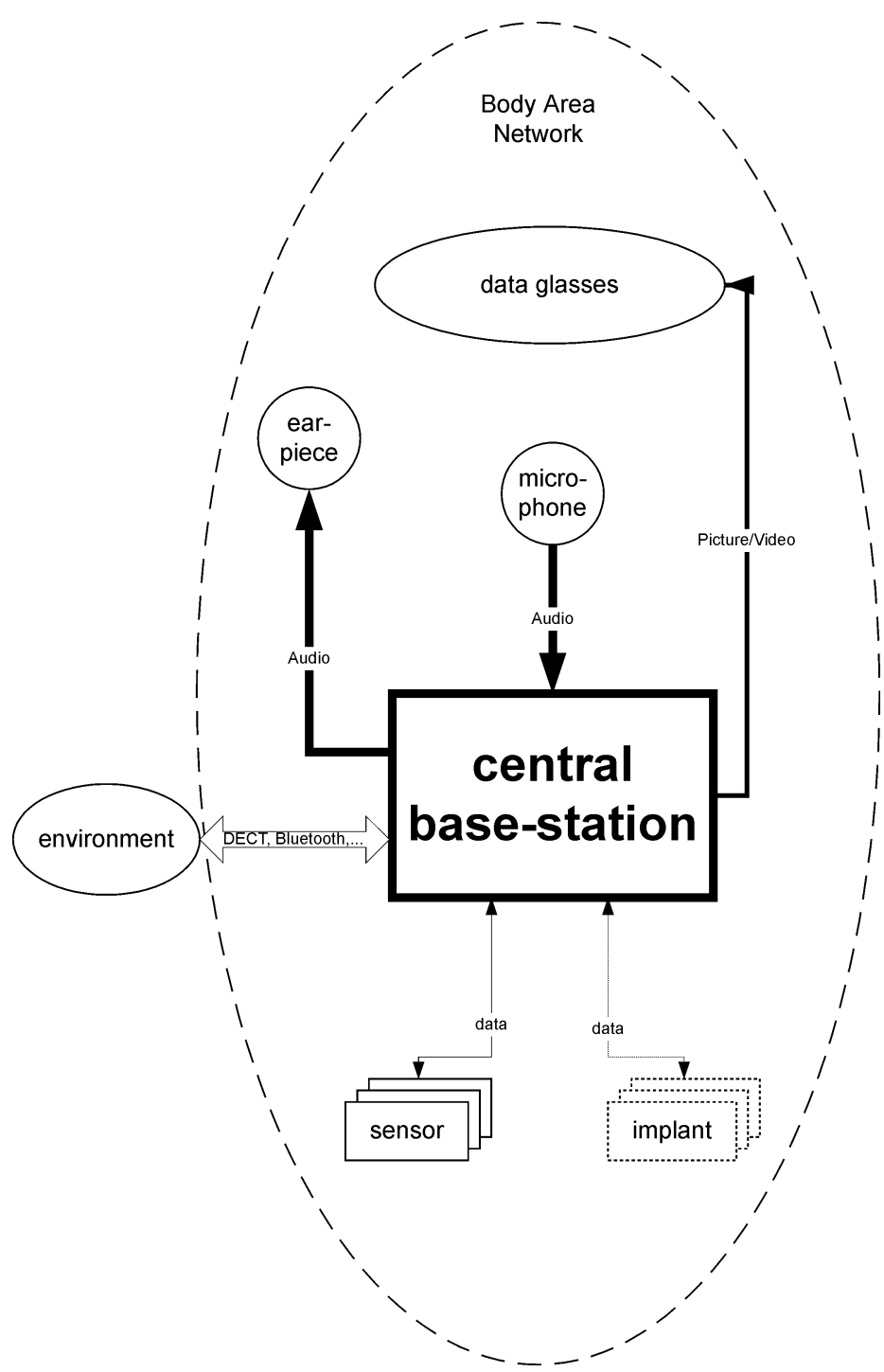

FIGURE 1 Possible parts within a body area network.

\section{TOPOLOGY OF MICRO-SYSTEMS AND MICRO-SYSTEM NETWORKS}

For micro-system networks we have to think of different network levels as shown in Figure 2. At the lowest complexity end are the micro-systems themselves. They measure, collect data or work as actors. The middle level will co-ordinate the communication between the backbone network and the micro-systems. In the case of passive micro-system this access-level will also deliver the needed energy. The back-bone network can be every existing or proprietary type of network.

Wireless micro-systems consist of some key parts as shown in Figure 3: antenna(s), battery and voltage control, LNA and PA, modulator and demodulator, channel encoder and decoder, memories, controller for data processing and power management and the different sensors or actors. 


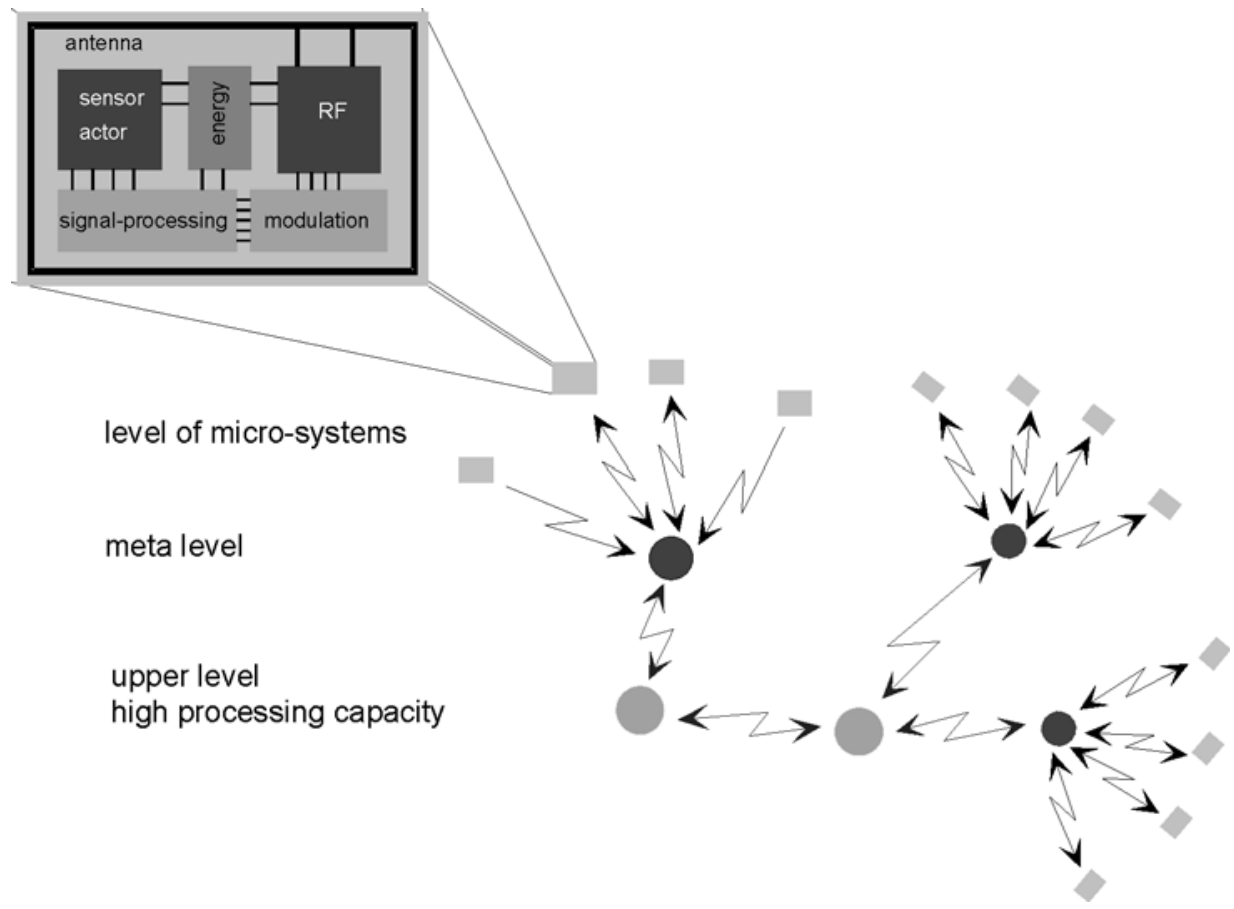

FIGURE 2 Principal topology of a micro-systems network.

There need not necessarily be two antennas, one for data transmission and one for power transmission. This can be done by one single antenna depending on the frequencies. In some applications where minimum failure rates are important a buffered solution using two frequencies should be preferred. This could be $125 \mathrm{kHz}$ for power transmission and $2.45 \mathrm{GHz}$ for data transmission in a short range scenario.

The following Figure 4 shows an example block diagram for the realisation of the RF part within an wireless micro-system. It represents the blocks antenna, band-pass-filter, LNA and

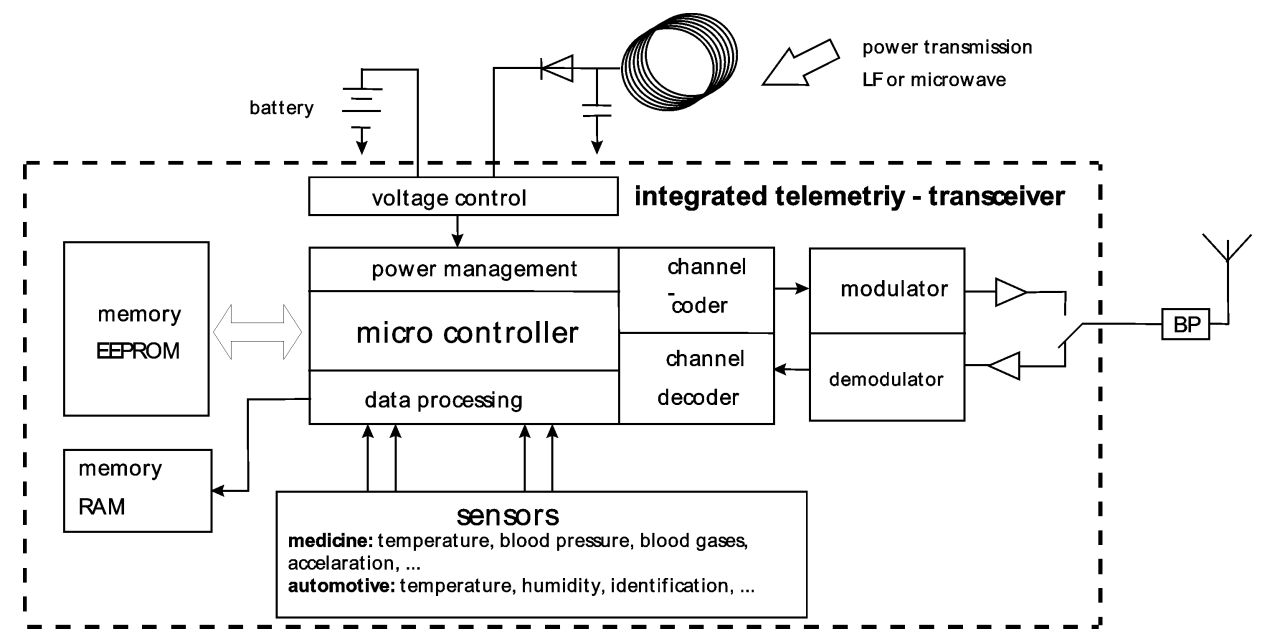

FIGURE 3 Principle diagram of a wireless micro-system. 


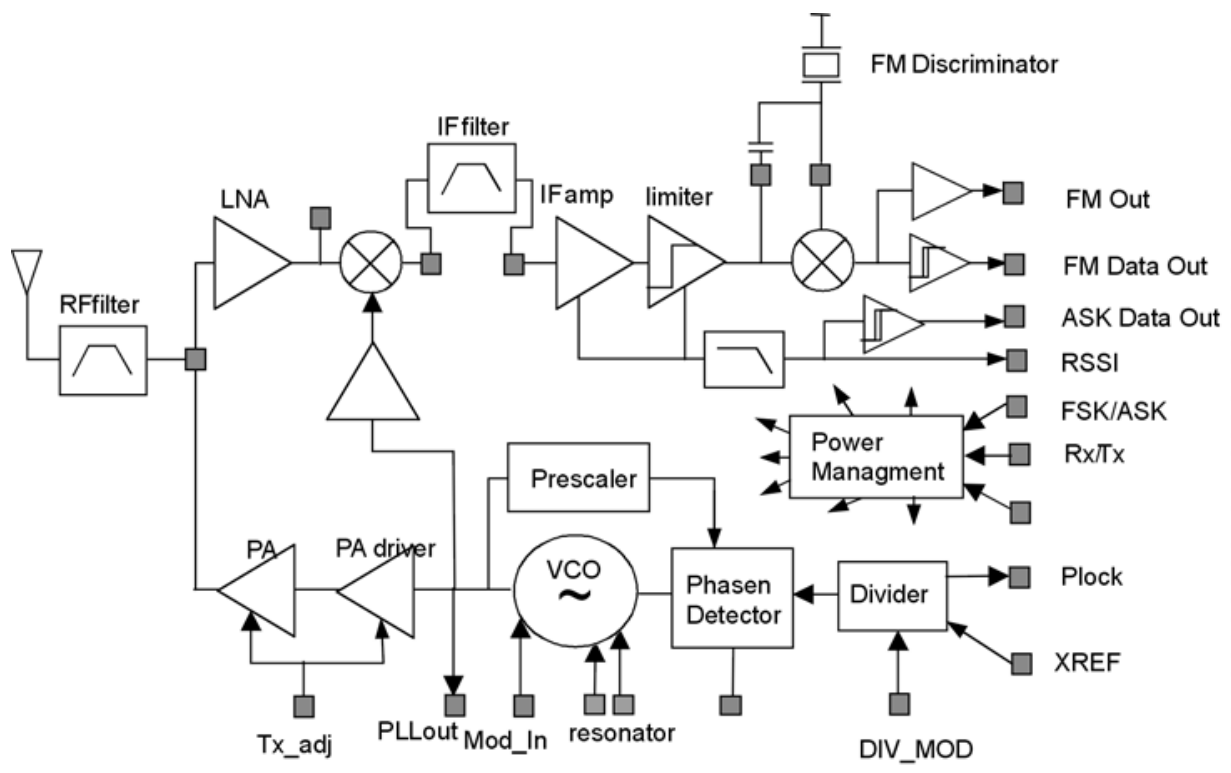

FIGURE 4 Block diagram for the realisation of the RF part of transceiver.

PA and modulator and demodulator of Figure 3. There is also an autonomous power management included that checks for data input and RF signals and disables actual not necessary blocks of the transceiver section. It was designed for minimum usage of external parts. In a more integrated solution this transceivers works as a building block and can be connected to the digital parts. Main item is the usage of one technology for analog, RF and digital circuits. For transmission frequencies up to $2.45 \mathrm{GHz}$ one can think of standard CMOS technologies.

We should have an eye on the different frequency ranges to be used within this scenarios. Most of the existing systems within transponder technologies use the ISM-bands at

- $125 \mathrm{kHz}$

- $13.56 \mathrm{MHz}$

- $26 \mathrm{MHz}$

- $434 \mathrm{MHz}$

- $868 \mathrm{MHz}$

- $915 \mathrm{MHz}$ (US)

- $2.45 \mathrm{GHz}$

- $5.8 \mathrm{GHz}$.

These bands have the advantage that no licensing of these bands is necessary unless transmitting power is too high. Depending on the different countries different power levels can be used. For some applications however it could make sense to use a licensed frequency band. If more and more wireless micro-system networks occur there is an increase in noise level and modulation schemes as well as access systems have to account for that.

\section{REQUIREMENTS FOR ANTENNAS}

Antennas for wireless micro-systems have some key requirements. The first to mention is their size. Because of the reduced size of the micro-systems themselves the antennas are physically and in most cases also electrically small. Because of this reduced size the key 


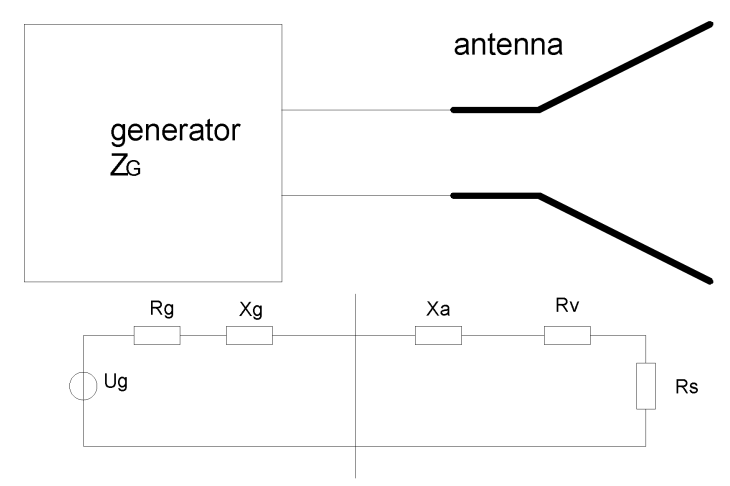

FIGURE 5 Circuit including source and antenna.

parameter for the antenna design is not the gain or directivity. Important for the design are the radiation efficiency and the matching to the circuit.

A equivalent circuit as shown in Figure 5 of an antenna consists of reactive part $X_{\text {ant }}$ and two real parts $R_{S}$ and $R_{V}$. The first one describes the inductive or capacitive part of the antenna. The ladder two are the radiation resistance $R_{S}$ which accounts for the radiated energy and the losses in the wires $R_{V}$. To have an optimal power transfer you need to match the circuit complex conjugate. This means the source should have an impedance of:

$$
\begin{aligned}
& Z_{G}=\operatorname{Re}\left(Z_{A}\right)-j \operatorname{Im}\left(Z_{A}\right) \\
& Z_{G}=R_{S}+R_{V}-j X_{A}
\end{aligned}
$$

or in other words, we have to make a resonator between source and antenna.

Another interesting topic is the placement of the antenna. The most sophisticated solution is the integration into the micro-system. But this is only applicable for the S- and C-band types. For the lower frequency bands there are two other approaches. One is to print the antenna on the PCB or on a flexible substrate which acts as support. Another is to use discrete antenna solutions in the form of single elements which can be mounted on the substrate or PCB. Maybe there is also the solution of using external filters as substrate for the antennas.

\section{TYPES OF ANTENNAS}

As mentioned before in the focus of wireless micro-systems will be small and low gain antennas. Here we can think of wire antennas like linear antennas (monopole, F-antenna, loops, helices), dielectric antennas and patch antennas.

\subsection{Loops}

Loops are used in great number as antennas for transponder systems working in the HF region $(13.56 \mathrm{MHz}, 26 \mathrm{MHz})$. Especially on credit card size transponders many loop turns can be implemented. Here we normally have passive systems getting their energy from the reader/writer station with low data rates. Energy and data are transmitted using inductive coupling between the stationary loops and the transponder loops. Advanced technologies 


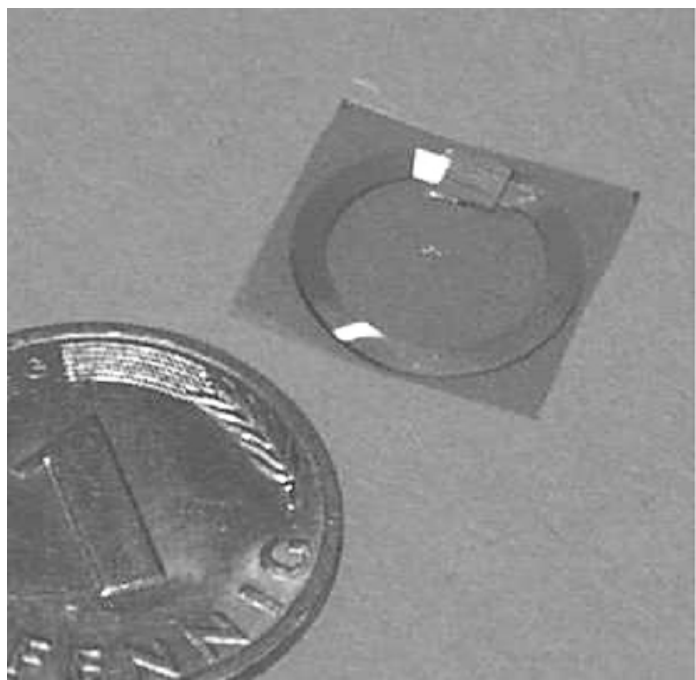

FIGURE 6 Transponder with transmission coil. (C) Fraunhofer Gesellschaft)

reach distances up to $1 \mathrm{~m}$. Essentially critical in this application are the orientations between base-station and transponder loops. They have to be parallel for maximum data and energy transmission.

To calculate the parameters of these antennas one has to simulate them in most cases. But for electrically small circular loops there are a number of approximation formulas.

For the imaginary part the inductance of the loop can be calculated as:

$$
L=\frac{1}{24.5 \times 10^{9}} \times \frac{n^{2} \times a^{2}}{8 a+11 c}
$$

where

$$
\begin{array}{ll}
L & \text { inductivity } \\
n & \text { number of turns } \\
a & \text { mean radius in } \mu \mathrm{m}: a=\left(r_{o}+r_{i}\right) / 2 \\
c & \text { width of turns in } \mu \mathrm{m}: c=r_{o}-r_{i}
\end{array}
$$

The two real parts are calculated using:

$$
R_{V}=\frac{1}{\sigma} \times \frac{l}{A}
$$

where
$\sigma \quad$ conductivity of material
$l \quad$ length of wire
A cross-section of wire.

For electrically small loops the radiation resistance can be calculated using:

$$
R_{S}=31200 \times\left(\frac{A}{\lambda^{2}}\right)^{2}
$$


FIGURE 7 Loops with 25 windings as mentioned in example. (C) Fraunhofer Gesellschaft)

where

$A \quad$ area of the loop using mean radius a

$\lambda$ wave-length.

Let us now make an example (Fig. 7). For a small transponder operating at $13.56 \mathrm{MHz}$ we have a 25 turn loop made on a $17 \mu \mathrm{m}$ copper cladded substrate. Width of the copper strips is $50 \mu \mathrm{m}$. The inner diameter of the loop is $3 \mathrm{~mm}$, the outer diameter is $8 \mathrm{~mm}$. This leads to:

$$
\begin{aligned}
L & =3.9 \mu \mathrm{H}\left(X_{A}=332 \Omega\right) \\
R_{V} & =8.8 \Omega
\end{aligned}
$$

The radiation resistance for this loop is so low that we can't speak of radiation. But there is inductive coupling between the reader and the transponder coils. To calculate the transmitted power we have to use the mutual coupling between the different coils in such a transmission system.

The coupling factor $M$ between reader and transponder coil can be calculated by:

$$
M=\frac{\mu_{0} \pi N_{1} N_{2}(a b)^{2}}{2\left(a^{2}+r^{2}\right)^{3 / 2}}
$$

where

$N_{1} \quad$ number of turns reader coil

$\mathrm{N}_{2} \quad$ number of turns transponder coil

a radius of reader coil

$b \quad$ radius of transponder coil

$r \quad$ distance between coils

$\mu_{0} \quad$ permeability of vacuum

\subsection{Linear Wire Antennas}

Linear wire antennas are the classic well-known antennas as used for broadcasting reception. For micro-systems we will have to make an approach that uses electrically short antennas. Types used here are:

- mono-pole

- dipole

- F-antenna

The first two are especially used at the higher frequencies: $2.45 \mathrm{GHz}$ and $5.8 \mathrm{GHz}$. Here they have a dimension of about $6 \mathrm{~cm}$ and $2.5 \mathrm{~cm}$ respectively, mono-pole half of that. But 


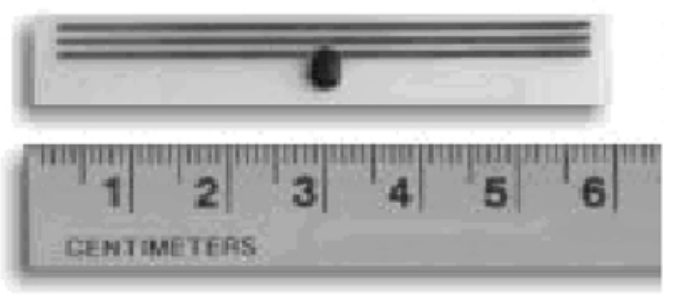

FIGURE 8 Transponder with dipole antenna on flexible substrate (C) Intermec Technologies Corporation).

it can clearly be seen that these dimensions have great impact on the size of the microsystems. So normally they are placed away from the chip and determine the size of the substrate (mostly flexible substrates).

F-antennas are widely used within integrated antenna solutions for cordless telephones. They act like mono-poles with the advantage of better matching parameters. For proper action they need a sufficiently sized ground plane.

Matching of the antenna to working frequency and amplifier impedance is done varying the lengths $a, d$ and $l$ as shown in Figure 9. The overall length $a+d+l$ determines the operating frequency whereas the distances a and $\mathrm{d}$ are used to get proper matching.

The following Figure 10 and Figure 11 shows simulated and measured input reflection coefficients. One can see that simulation and measurement agree quite well. The simulation was done using Agilents Momentum field solver.

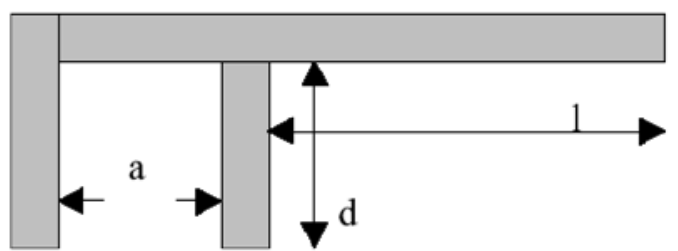

FIGURE 9 Parameters of F-antenna.

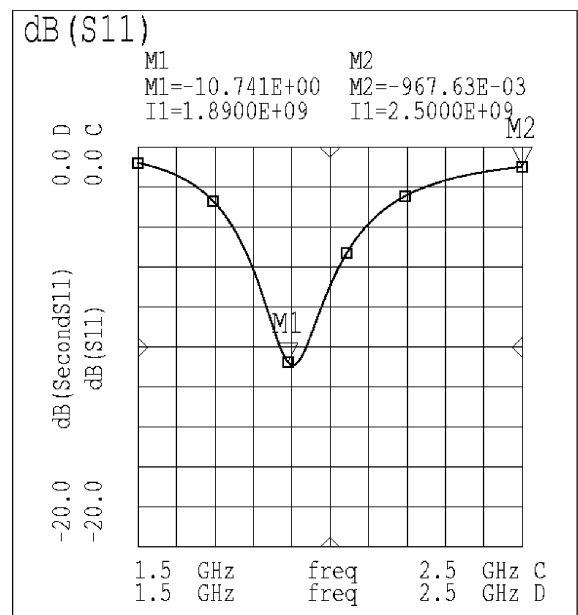

FIGURE 10 Simulation of $1.9 \mathrm{GHz}$ F-antenna, input reflection coefficient. 


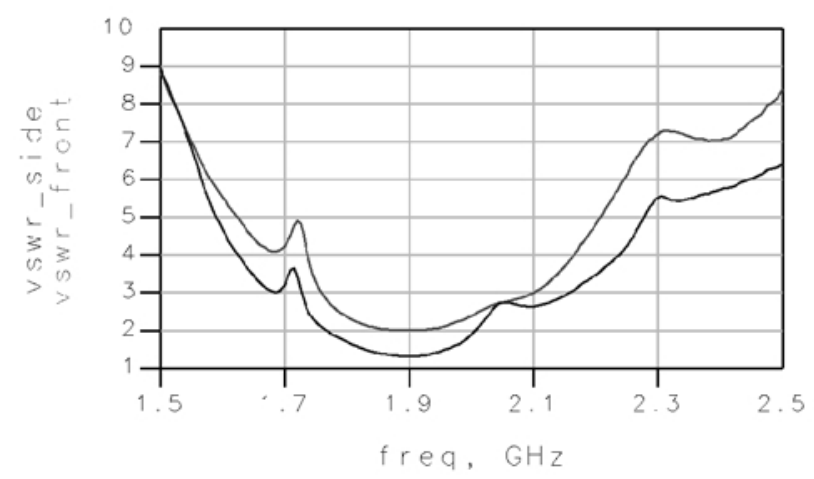

FIGURE 11 Measured input VSWR.

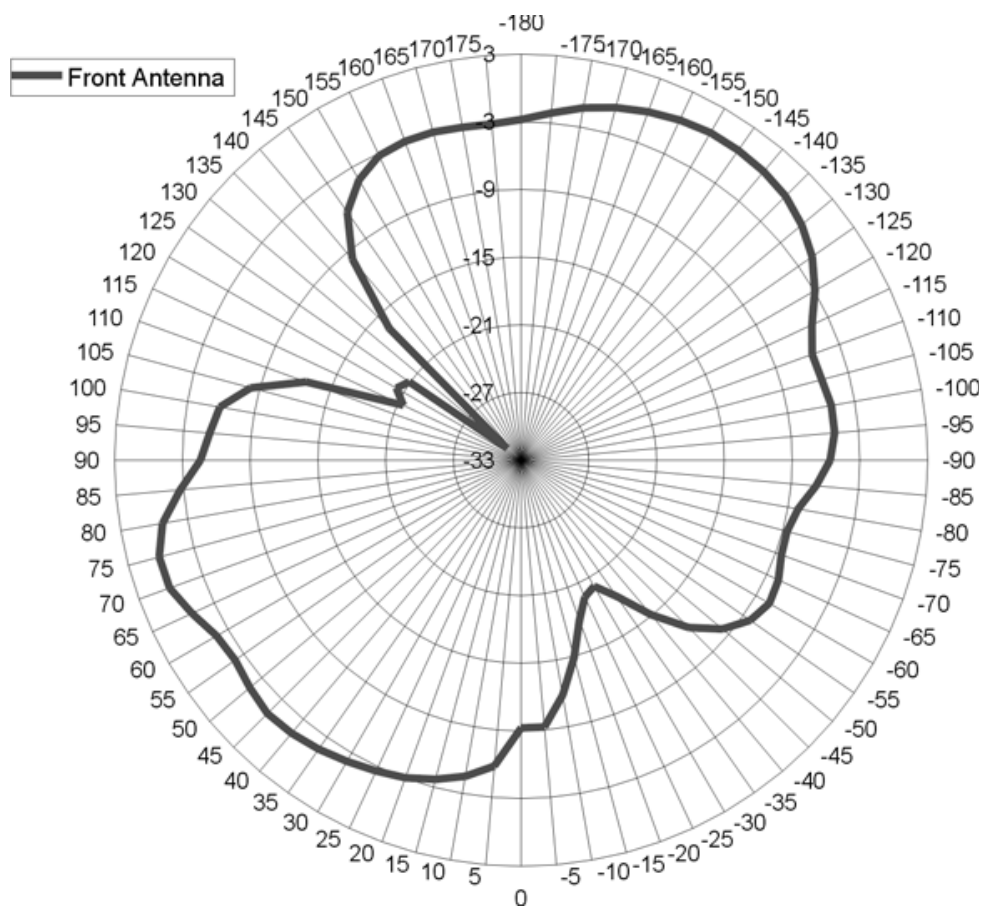

FIGURE 12 Azimuthal pattern of a realised F-antenna.

In free space wire antennas like mono-poles and dipoles are omni-directional in their azimuthal pattern. Due to the needed ground-plane for F-antennas this is not possible. In the ideal case where the ground-plane extends to infinity a hemispherical pattern is possible. Unfortunately the integrated versions do not have the possibility of large ground-plane sizes. So the pattern deteriorates. The following Figure 12 shows a measured pattern.

\subsection{Patch Antennas}

Patch antennas are very much in usage at microwave frequencies. Within wireless microsystems we could have the problem of size of the radiating element. Minimum size for a 

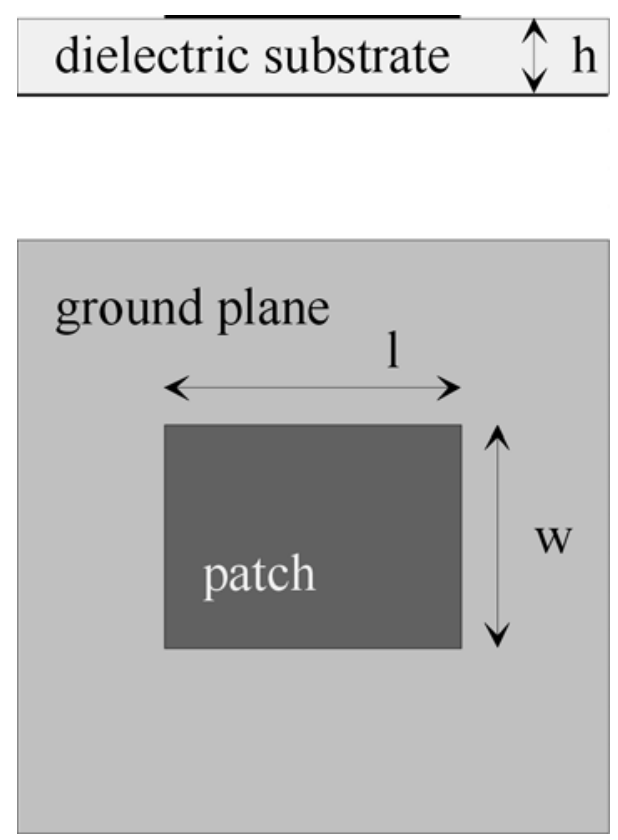

FIGURE 13 Patch antenna over ground plane.

patch is a quarter of a wavelength. Without using dielectric substrates this would lead to a dimension of about $3 \mathrm{~cm}$ in length. A half wavelength patch would have a size of $6 \mathrm{~cm}$. But there is the possibility of using dielectric materials.

To get a reasonable reduction of patch-length we will have to use substrates with quite high dielectric constants as the reduction only works by the square root of the dielectric constant. The dielectric constant itself must be replaced by an effective dielectric constant because only parts of the electromagnetic waves will be within the substrate.

$$
l=\frac{l_{0}}{\sqrt{\varepsilon_{r, \mathrm{eff}}}}
$$

where

$l \quad$ length of patch

$l_{0} \quad$ length in free space $\left(\lambda_{0} / 2\right)$

$\varepsilon_{r, \text { eff }}$ effective dielectric constant

$$
\varepsilon_{r, \mathrm{eff}}=\frac{\varepsilon_{r}+1}{2}+\frac{\varepsilon_{r}-1}{2}\left[1+12 \frac{h}{w}\right]^{-1 / 2}, \quad \frac{w}{h}>1
$$

where

$$
\begin{array}{ll}
\varepsilon_{r} & \text { dielectric constant } \\
h & \text { thickness of substrate } \\
w & \text { width of patch }
\end{array}
$$

Feeding of the patch can for example be done using a microstrip line. This would accomplish that micro-system and patch are located upon the same substrate. 
Some relative dielectric constants for some materials are shown in the following table:

$\begin{array}{lc}\text { Aluminium oxide } & 8.8 \\ \text { Magnesium oxide } & 9.6 \\ \text { Silicon } & 12 \\ \text { BaTiOxide } & 39 \\ \text { (BaLn)TiOxide } & 80 \\ \text { Titania } & 100\end{array}$

\subsection{Dielectric Antennas}

Dielectric antennas consist of dielectric resonators or dielectrically loaded wire antennas.

\subsection{Helices}

Normal mode helices are the most common antennas in mobile telephones. They consist of wound wire with a perimeter much lower than the wave-length of the used frequency. They have the advantage that they are mechanically very stable (like a spring) and are very cheap in manufacturing. For the usage within wireless micro-systems there are different disadvantages especially regarding the connections between the antenna and the RF part. Helices can not be integrated into the circuits.

\section{FUTURE TRENDS}

Future systems will have a demand for wireless micro-systems. They can be applied in many different application scenarios as mentioned in the introduction. Especially body area networks to monitor vital functions or to aid the people will be an upcoming thing. But also in harsh environments like in production and manufacturing there will be a great demand for wireless micro-systems for measuring purposes. Especially intelligent transponder systems to aid the production will see a great future.

As integration levels get higher also smaller and compact antennas will be needed. Two things will occur then: antennas will get smaller and the usage of dielectric material will increase. On the other hand the solution could also be the usage of higher frequencies but there may be technological problems.

\section{CONCLUSION}

Goal of this paper was to give an overview of wireless micro-system networks and their specific requirements. In detail we focussed on the principal topology of these networks as well as the single micro-systems. Main topic were the antennas-which make the connection to the outer world. Different antenna types were described, some in detail and some just mentioned.

\section{References}

[1] Johnson, R. C. (1993). Antenna Engineering Handbook, 3rd ed. McGraw-Hill, New York.

[2] Balanis, C. A. (1997). Antenna Theory - Analysis and Design, 2nd ed. John Wiley, New York. 
[3] Wadell, B. C. (1991). Transmission Line Design Handbook. Artech House, Norwood.

[4] Sainati, R. A. (1996). CAD of Microstrip Antennas for Wireless Applications. Artech House, Norwood.

[5] Fulimoto, K. et al. (1993). Small Antennas. Research Studies Press, Taunton.

[6] Janzen, G. (1986). Kurze Antennen. Frankh, Stuttgart.

[7] Wansch, R. et al. (1999). Drahtlose Mikrosysteme - Einsatzmöglichkeiten in der Medizintechnik. In: Tagungsband zum 8. GMM Workshop Methoden und Werkzeuge zum Entwurf von Mikrosystemen, Berlin, 2.-3. Dez., S. $61-65$

[8] Wansch, R. et al. (1997). Struktur, Aufbau und Modellierung drahtloser Mikrosystemem. In: Tagungsband zum 6. GMM Workshop Methoden und Werkzeuge zum Entwurf von Mikrosystemen, Paderborn, 5.-6. Dez., S. 93-100.

[9] Wansch, R. et al. An integrated F-antenna for diversity reception in a DECT data transmission module. 2000 IEEE AP-S International Symposium, pp. 278-281. 

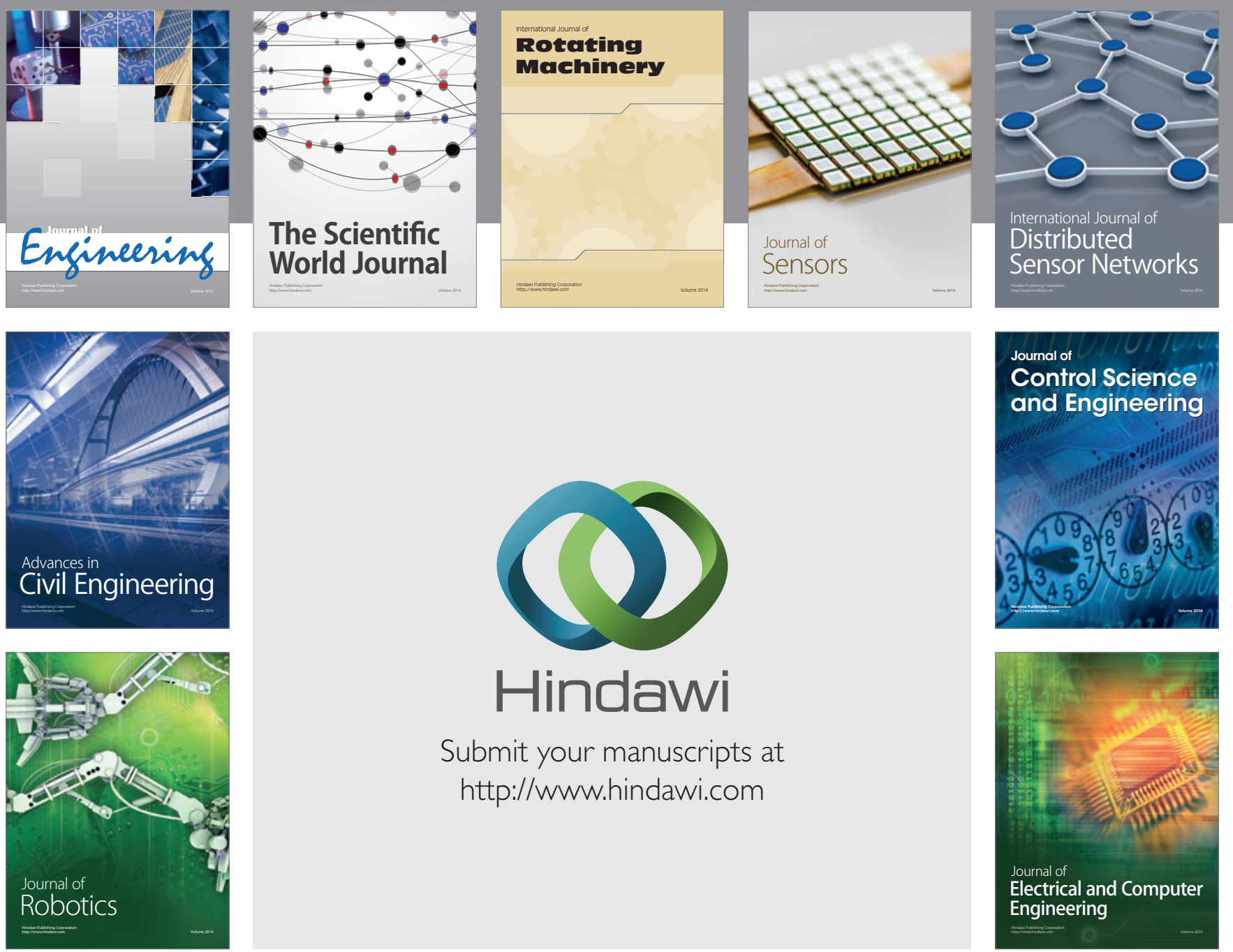

Submit your manuscripts at

http://www.hindawi.com
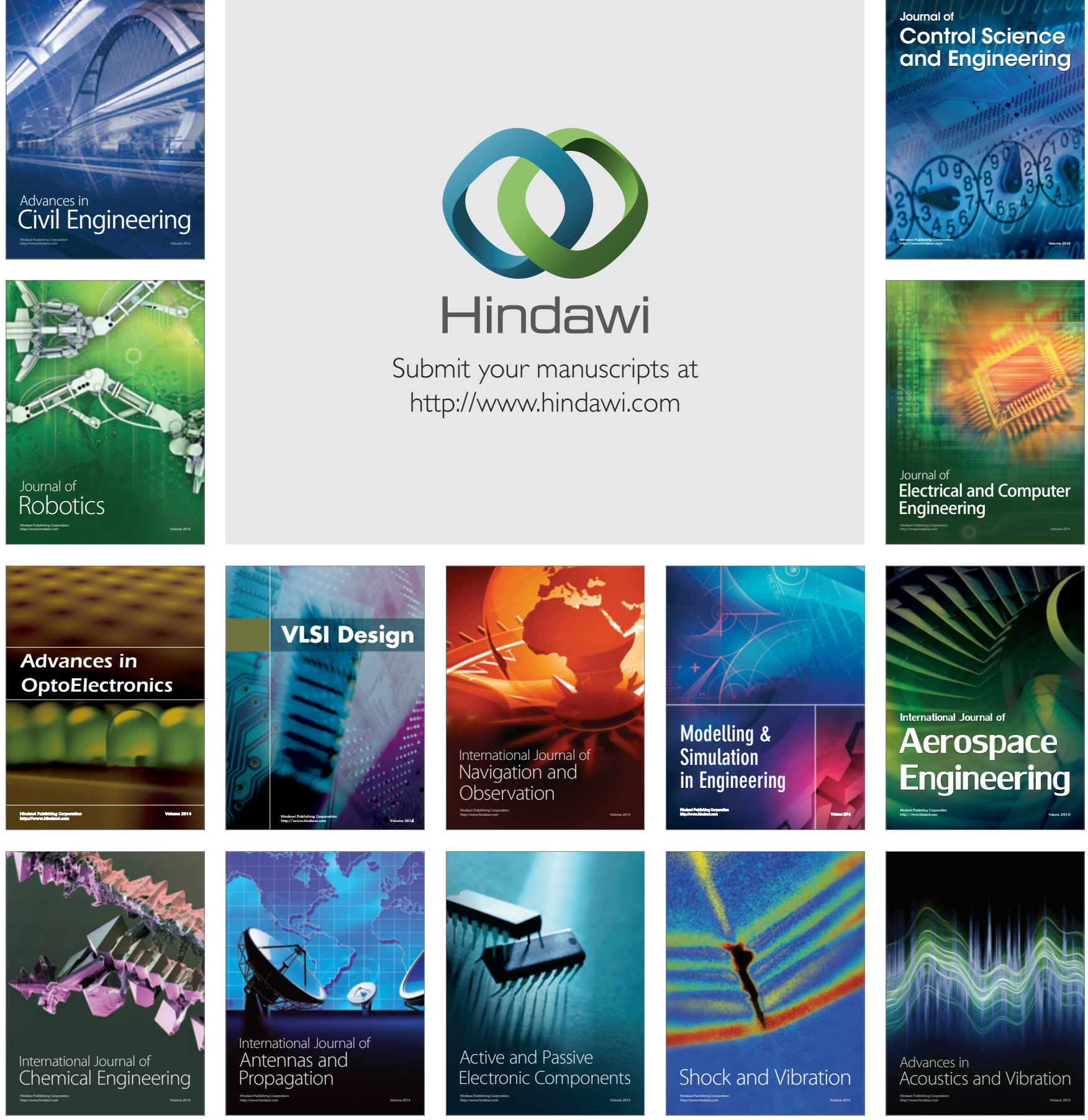